\title{
Evaluating cementation factor for bioturbated sandstones, Bhuj Formation, Kachchh Basin, India: a novel approach using triple-porosity model
}

\author{
Ajendra Singh ${ }^{1} \cdot$ Jason Dcunha ${ }^{1} \cdot$ Bhawanisingh G. Desai ${ }^{1}[$
}

Received: 16 September 2021 / Accepted: 4 February 2022 / Published online: 25 February 2022

(c) The Author(s) 2022

\begin{abstract}
Cementation factor has a crucial role in evaluating volumetric reserves for heterogeneous clastic reservoir. Bioturbation is a prominent source of heterogeneity existing in hydrocarbon-bearing formation across the world. The effect of bioturbation on the petrophysical properties of the clastic has not been comprehensively understood yet, especially its effect on cementation factor estimation. The precise description of such properties is beneficial in developing better volumetric estimates and optimizing field development planning. The present work discusses an approach to characterize cementation factor in bioturbated clastic Bhuj Formation, Kachchh Basin, India. In order to ascertain the cementation exponent for bioturbated media, an improved triple-porosity model is proposed by quantifying the total porous volume into three components, namely matrix 1, matrix 2 and bioturbated region. An equivalent resistance model is then developed by identifying the series and parallel relation between the two matrix components and the burrow. The experimental observations of electrical response indicated large variation in resistivity in vertical cores compared to horizontal cores. The decreased resistivity is due to the vertically aligned burrow which due to their enhanced porosity provides less tortuous path for current to flow. The tripleporosity model is validated with different porosity value of matrix 1, matrix 2 and burrow, and a cementation factor of 2.8 for higher bioturbated samples and 3 for lower bioturbated samples is obtained. This validates the previous understanding of enhanced flow and storage property and thereby produces a consistent way to evaluate total cementation factor. The correct estimation of cementation factor helps in precise evaluation of water saturation in bioturbated reservoirs.
\end{abstract}

Keywords Bioturbation $\cdot$ Cementation factor $\cdot$ Heterogeneity $\cdot$ Formation resistivity factor

$\begin{array}{ll}\text { Abbreviations } \\ \text { FRF } & \text { Formation resistivity factor } \\ \text { LCR } & \text { Meter inductance capacitance resistance meter } \\ \text { BI } & \text { Bioturbation index } \\ \tau & \text { Tortuosity } \\ a & \text { Tortuosity factor } \\ m_{t} & \text { Porosity factor (cementation factor) of triple-poros- } \\ & \text { ity system } \\ m_{1} & \text { Cementation factor of matrix } 1\end{array}$

Bhawanisingh G. Desai

bhawanigd@gmail.com; bhawanisingh.desai@spt.pdpu.ac.in

Ajendra Singh

ajjusingh1989@gmail.com

Jason Dcunha

jasond9996@gmail.com

1 School of Petroleum Technology, Pandit Deendayal Energy University, Raisan, Gandhinagar, Gujarat, India $m_{2} \quad$ Cementation factor of matrix 2

$m_{t} \quad$ Total cementation factor of triple-porosity system

$m_{B} \quad$ Cementation factor of burrow in triple-porosity system

$n \quad$ Water saturation factor

$r_{m} \quad$ Resistance of matrix 1 and matrix 2 when the system is $100 \%$ saturated with brine

$r_{m 1} \quad$ Resistance of matrix 1 when the system is $100 \%$ saturated with brine

$r_{m 2} \quad$ Resistance of matrix 2 when the system is $100 \%$ saturated with brine

$r_{B} \quad$ Resistance of bioturbated region (burrow) when the system is $100 \%$ saturated with brine

$r_{t} \quad$ Total resistance of triple-porosity system when $100 \%$ saturated with brine

$R_{m} \quad$ Resistivity of matrix 1 and matrix 2 when the system is $100 \%$ saturated with brine

$R_{m 1} \quad$ Resistivity of matrix 1 when the system is $100 \%$ saturated with brine 


$\begin{array}{ll}R_{m 2} & \begin{array}{l}\text { Resistivity of matrix } 2 \text { when the system is } 100 \% \\ \text { saturated with brine }\end{array} \\ R_{B} & \begin{array}{l}\text { Resistivity of bioturbated region (burrow) when the } \\ \text { system is 100\% saturated with brine }\end{array} \\ R_{t} & \begin{array}{l}\text { Total resistivity of triple-porosity system when } \\ 100 \% \text { saturated with brine }\end{array} \\ R_{w} & \begin{array}{l}\text { Resistivity of water } \\ S_{w}\end{array} \\ \varnothing & \text { Water saturation of triple-porosity system } \\ \varnothing_{m 1} & \text { Total porosity } \\ \varnothing_{m 2} & \text { Porosity of matrix 1 } \\ \varnothing_{B} & \text { Porosity of bioturbated region (burrow) }\end{array}$

\section{Introduction}

Bioturbation in clastic reservoirs is one of the least analyzed phenomena resulting in heterogeneity, which is primarily the sediment reworking or modification in the textural and fabric attributes of sediments (Dorador et al 2021; Gingras et al. 1999, 2002, 2012; Meadows and Tait 1989; Pemberton and Gingras 2005; Perret et al. 1999; Pierret et al. 2002). Various researchers have postulated the effect of bioturbation on the reservoir quality and heterogeneity, resulting in either enhancing or diminishing the petrophysical properties (Pemberton and Gingras 2005; Dorador et al 2021).The bioturbation results in a generation of complex network of burrows filled with contrasting sediments than the surrounding matrix. These burrows fill introduces anisotropy in porosity and permeability (Fig. 1); when the burrows are filled with coarser grain sediments, they tend to enhance the bulk storage and flow behavior, thereby increasing reserve estimates; on the contrary, when burrows have less porosity than the surrounding, they reduce the volumetric estimates

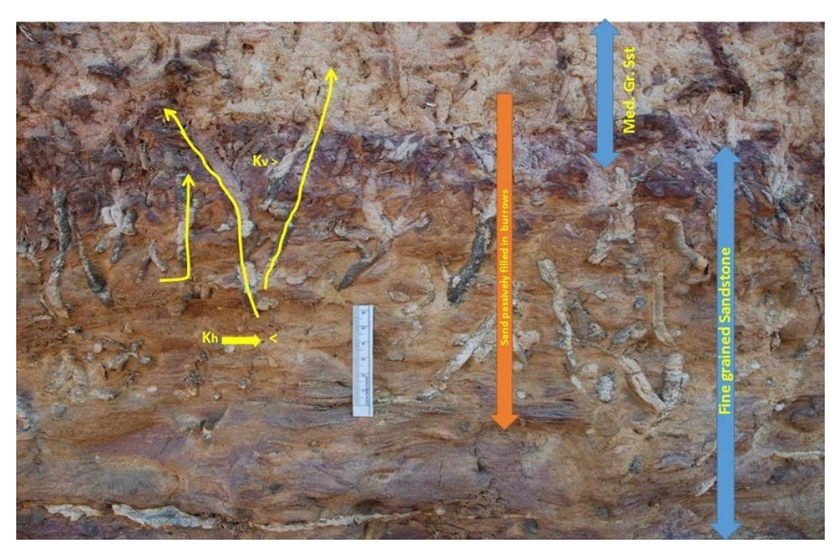

Fig. 1 Outcrop view of the permeability anisotropy and dual porosity in bioturbated sandstones of Early Cretaceous Ghuneri Member showing high contrast between matrixes and burrow sediment. Note that the burrows provide higher vertical permeability as compared to horizontal of reservoir (Pemberton and Gingras 2005; Gingras et al 2012; Gingras and Pemberton, 2014). Any decision pertaining to field development planning and volumetric estimation would require understanding of flow behavior of the reservoir. The burrow-induced alteration in sedimentary fabric will affect the bulk behavior of the reservoir properties as well (Gingras et al. 1999, 2007; Pemberton and Gingras 2005). Hence, understanding of flow behavior of a bioturbated reservoir is key to developing an economically efficient recovery scheme.

An efficient means of characterizing the effects of bioturbation is utilizing the analogy of hydraulic properties and electric properties as fluid and current both flow through identical paths in porous media (Pirson 1958). The equivalent resistivity response of a rock can be modeled as a twocomponent parallel network with conducting fluid as one and insulating rock matrix as other (Givens and Schmidt 1987). The early work by Archie (1942) provides useful empirical relation between electrical resistivity and porosity: The formation resistivity factor (FRF) tends to characterize the resistivity response of fluid saturated formation. The Archie's parameters such as cementation factor $(m)$, tortuosity factor $(a)$ and saturation factor $(n)$ are important factors needed to be determined for evaluating the fluid saturation in the porous media. The inexact description of such parameters can generate a significant error in water saturation values, thus underestimating or overestimating the hydrocarbon saturation in the reservoir. The Archie law, however, has some limitations that limit its applicability to all rocks. This includes assumption such as homogeneous formation unimodal intergranular porosity and also some non-geometric factors like water wet formation, no surface or conductive minerals to be present (Herrick 1989). Therefore, for those non-Archie rocks that do not satisfy the condition laid by Archie's law a different approach is needed to be devised. In general, extensive work on carbonate has given acceptance to dual-porosity approach of matrix and fracture (Berg 2006; Aguilera 1976, 2010; Aguilera and Aguilera 2003, 2004; Rasmus 1983), but the fracture architecture is quite different than burrow; hence, it cannot be applied for bioturbated media. A triple-porosity approach proposed for carbonate formation by Xia et al. (2012) provides some encouraging insights by characterizing the porous media in macropore, mesopore and micropore arrangement. But due to its limitation to low porosity and permeability formations, the electrical network model developed is debatable.

In our understanding, the bioturbated clastic will result in a non-Archie rock type. The present work discuses a tripleporosity approach where the electrical response of bioturbated media is characterized as an equivalent resistivity of three components: matrix 1, matrix 2 and burrow. The investigation discusses the applicability of the equivalent network model along with the evaluation of cementation factor in 
both matrix and burrow. Then, a formulation to evaluate total cementation factor $m_{t}$ of the bioturbated media is discussed which is validated by the experimental observation from two different degrees of bioturbation. The proposed model provides a new approach to evaluate the cementation factor in bioturbated formation.

\section{Geology of the studied area}

Kachchh Basin is a peri-cratonic rift in the northwestern part of the western continental margin of India (Biswas 1977, 2016), likely to be the eighth producing basin of India. It has been classified as the Category II Basin (proven petroliferous awaiting commercial production). It is bounded by the Nagar Parkar fault in the north, Radhanpur-Barmer arch in the east and North Kathiawar fault toward the south. The stratigraphic succession, ranging in age from Middle Jurassic to Holocene, is exposed in the onshore part of Kachchh Basin. The lithostratigraphic sequence of the Mainland comprises the Jhurio, Jumara, Jhuran and the Bhuj formations (Biswas 2016). The studied Bhuj Formation belongs to the Cretaceous Age deposits of marine to deltaic depositional environment. The Bhuj Formation is divided into Ghuneri, Ukra and Upper members (Biswas 2016; Desai and Saklani, 2012; Desai and Chauhan, 2021). The Ghuneri member is characterized by highly bioturbated; ferruginous, medium- to coarse-grained cross-bedded sandstones, alternating with ferruginous, micaceous, laminated, fine-grained sandstone with minor shales (Desai and Saklani, 2012; Desai and Chauhan, 2021).

The Ghuneri member is characterized by the cyclic repetition of ferruginous bands (highly bioturbated), shales and sandstones (Biswas 2016; Desai and Saklani 2012).

The studied outcrop section of the Ghuneri member has a different amount of bioturbation present in it. Therefore, based on the lithological variation and amount of burrow activity, it is further classified under five different subunits. The studied unit has a moderate to well-sorted quartz with ferruginized cement; the burrow is actively filled with evidence of weathering and dissolution (Table 1).

The present work implements Bioturbation Index (BI) (Table 2) scheme which quantifies the alteration in primary sedimentary facies and burrow density and their overlap proposed by Taylor and Goldring (1993)

\section{Methodology}

The outcrop samples of Ghuneri Member, Bhuj Formation were sampled from different locations of Kachchh Basin (Fig. 2). These block samples were cored vertically and horizontally to the bedding plane, the vertical cores were indicated by "V," while the horizontal by " $H$ " in the sample id. A total of 39 core samples were plugged, trimmed and endface grinded. After drying samples to remove inclusion from plugging and other core preparation techniques, these were analyzed for their porosity estimation using vacuum saturation method. The sample pore volume is measured using gravimetric analysis of sample weight before and after the saturation and bulk volume. The core samples were saturated using a vacuum pump for $48 \mathrm{~h}$ with brine solution $(\mathrm{NaCl})$ of concentration $5 \%$ by weight. In order to perform resistivity experiments, an electrically conductive fluid is needed to be present in the pore volume, $\mathrm{NaCl}$ solution served the purpose. The formation resistivity factor (FRF) measurements of the samples were performed using a bench-type Falcon (LCR-010B) LCR meter at four different frequencies $(1 \mathrm{kHz}$, $10 \mathrm{kHz}, 100 \mathrm{~Hz}, 120 \mathrm{~Hz}$ ) using a two-electrode arrangement (Fig. 3a) in ambient and unstressed condition. The samples were fixed using a bar clamp, and copper plates and resistive foam at both ends were placed to provide a sturdy support as shown (Fig. 3b). The alligator clips provided the connection between the sample and LCR meter. The contact resistance artifact is minimized by the sample contacts (Bloss and Berosian 2015). In a two-electrode arrangement, generally higher frequency is preferred due to low phase angle and minimal capacitance (Mcphee et al. 2015). Hence, the measurements obtained at $10 \mathrm{kHz}$ were used for evaluating the

Table 1 Bioturbation classification scheme proposed by Taylor and Goldring (1993)

\begin{tabular}{lll}
\hline $\begin{array}{l}\text { Bioturbation Index } \\
\text { (BI) }\end{array}$ & Percent bioturbated & Classification \\
\hline 0 & 0 & No bioturbation \\
1 & 1 to 4 & Sparse bioturbation, bedding distinct and few discrete traces \\
2 & 5 to 30 & Low bioturbation, bedding distinct, low trace density and escape structures often common \\
3 & 31 to 60 & Moderate bioturbation, bedding boundaries sharp, trace discrete and overlap rare \\
4 & 61 to 90 & High bioturbation, bedding boundaries indistinct and high trace density with overlap common \\
5 & 91 to 99 & Intense bioturbation, bedding completely disturbed \\
6 & 100 & Complete bioturbation and sediment reworking \\
\hline
\end{tabular}


Table 2 Data showing samples along with their bioturbation intensity, dimensions and measured porosities

\begin{tabular}{|c|c|c|c|c|}
\hline Core name & $\begin{array}{l}\text { Biotur- } \\
\text { bation } \\
\text { intensity }\end{array}$ & Length (cm) & Diameter $(\mathrm{cm})$ & $\begin{array}{l}\text { Porosity } \\
\text { (fraction) }\end{array}$ \\
\hline MP-H a & 2 & 3.73 & 2.49 & 0.17 \\
\hline MP-H b & 2 & 4.01 & 2.49 & 0.14 \\
\hline MP-H c & 2 & 2.09 & 2.49 & 0.14 \\
\hline MP-V a & 2 & 4.77 & 2.51 & 0.18 \\
\hline MP-V b & 2 & 2.67 & 2.48 & 0.15 \\
\hline MP-V c & 2 & 3.65 & 2.44 & 0.14 \\
\hline $\mathrm{J}-\mathrm{IH}$ a & 2 & 4.17 & 2.57 & 0.18 \\
\hline $\mathrm{J}-1 \mathrm{~V} \mathrm{a}$ & 2 & 3.33 & 2.48 & 0.18 \\
\hline KT-IV & 2 & 3.21 & 2.5 & 0.13 \\
\hline $\mathrm{J}-\mathrm{IH} \mathrm{b}$ & 2 & 3.33 & 2.48 & 0.23 \\
\hline KT-IV & 2 & 2.86 & 2.48 & 0.18 \\
\hline $\mathrm{J}-1 \mathrm{~V} \mathrm{~b}$ & 2 & 6.32 & 2.5 & 0.23 \\
\hline KT-IV a & 2 & 5.67 & 2.51 & 0.23 \\
\hline KT-IV b & 2 & 5.31 & 2.48 & 0.24 \\
\hline GE-IV a & 4 & 2.85 & 2.45 & 0.18 \\
\hline GE-IH a & 4 & 2.42 & 2.49 & 0.15 \\
\hline GE-1V b & 4 & 3.04 & 2.5 & 0.21 \\
\hline GE-1H b & 4 & 3.45 & 2.48 & 0.16 \\
\hline GE-1H c & 4 & 2.91 & 2.47 & 0.18 \\
\hline GE $1 \mathrm{~V} \mathrm{c}$ & 4 & 4.08 & 2.49 & 0.25 \\
\hline W-IV a & 5 & 3.54 & 2.51 & 0.12 \\
\hline $\mathrm{W}-1 \mathrm{~V} \mathrm{~b}$ & 5 & 3.47 & 2.45 & 0.16 \\
\hline GE $5 \mathrm{~V}$ a & 5 & 3.21 & 2.48 & 0.13 \\
\hline GE $3 \mathrm{~V}$ a & 5 & 3.05 & 2.46 & 0.14 \\
\hline GE $3 \mathrm{~V} \mathrm{~b}$ & 5 & 4.01 & 2.5 & 0.16 \\
\hline GE $3 \mathrm{~V} \mathrm{c}$ & 5 & 5.11 & 2.46 & 0.15 \\
\hline $\mathrm{GE} 3 \mathrm{H} \mathrm{a}$ & 5 & 2.41 & 2.43 & 0.13 \\
\hline $\mathrm{GE} 3 \mathrm{H} \mathrm{b}$ & 5 & 5.76 & 2.49 & 0.16 \\
\hline GE $5 \mathrm{~V} \mathrm{~b}$ & 5 & 2.11 & 2.48 & 0.08 \\
\hline GE $5 \mathrm{~V} \mathrm{c}$ & 5 & 2.43 & 2.49 & 0.13 \\
\hline GE $5 \mathrm{H}$ a & 5 & 2.44 & 2.49 & 0.14 \\
\hline GE $5 \mathrm{H} \mathrm{b}$ & 5 & 4.22 & 2.49 & 0.15 \\
\hline $\mathrm{W}-\mathrm{V}$ & 5 & 2.76 & 2.48 & 0.16 \\
\hline W-3H & 5 & 3.32 & 2.47 & 0.19 \\
\hline $\mathrm{W}-1 \mathrm{H}$ a & 5 & 2.46 & 2.5 & 0.13 \\
\hline $\mathrm{W}-1 \mathrm{H} \mathrm{b}$ & 5 & 5.71 & 2.49 & 0.16 \\
\hline GE-3H c & 5 & 3.67 & 2.51 & 0.2 \\
\hline
\end{tabular}

Note in the core name; initial two letters are sample name, and $\mathrm{H} / \mathrm{V}$ at the end of the sample code corresponds to the horizontal or vertical direction

sample resistivity. The resistance measured from the LCR meter was converted into resistivity by using geometrical factor $(\mathrm{K})$ and length of the samples $(\mathrm{L})$ as mentioned in the following relation:

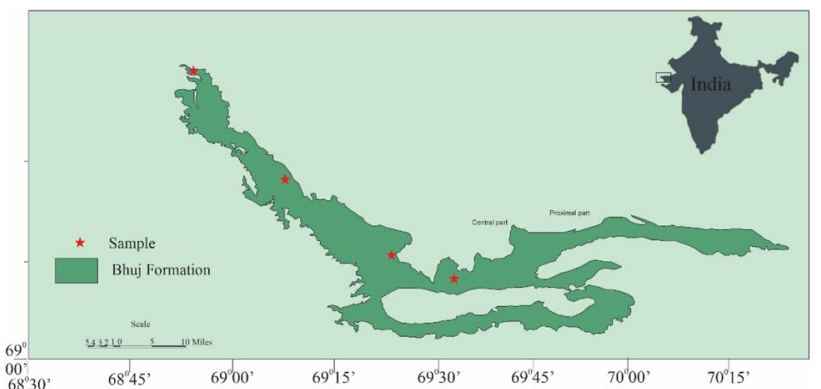

Fig. 2 Geological and outcrop exposures of Bhuj Formation in Kachchh Basin showing samples locations; note the samples were taken across the basin to grab the regional variation. (after Biswas and Deshpande, 1970)

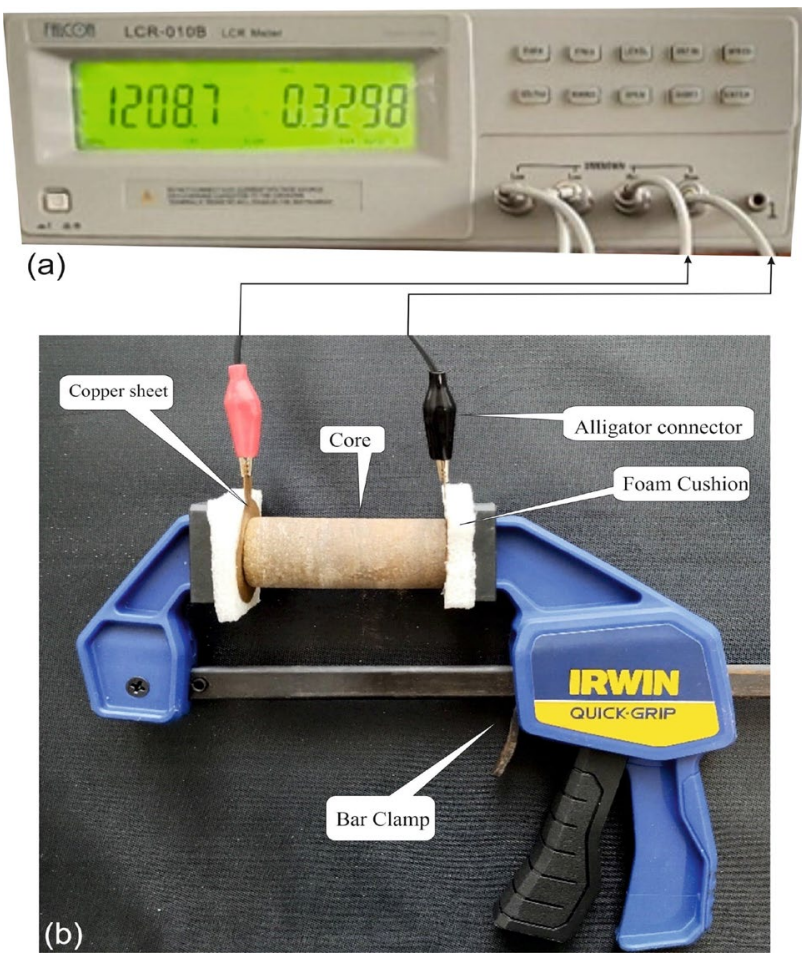

Fig. 3 Experimental setup for measuring the Resistance using a LCR010B meter connected with b core plug fixed in bar clamp with a copper sheet at both ends connected to LCR meter by alligator connector

$\rho=K * R$

$K=\sqrt{\frac{a_{1} * a_{2}}{l}}$

where $K=$ geometrical factor in meters (m), $a_{1}, a_{2}=$ effective cross-sectional area of sample in contact with each electrode in $\mathrm{m}^{2}, l=$ length of the samples in $(\mathrm{m}), \rho=$ resistivity in ohm meter $(\Omega-\mathrm{m}), R=$ resistance measured in ohm $(\Omega)$. 


\section{Triple-porosity model}

The proposed triple-porosity model assumes the bioturbated sandstone specimen to be composed of three different components, namely matrix 1 , matrix 2 and burrow. Figure 4 illustrates a photograph of the heterogeneous bioturbated core plug depicting the (i) burrow, (ii) matrix 1 and (iii) matrix 2 in the specimen. In further sections of this paper, subscript (1) is used to represent matrix 1, subscript (2) for matrix 2 , and subscript (b) for burrow.

\section{Electrical analogy}

Various researchers including Archie (1942) and Givens and Schmidt (1987) through extensive experimentation observed that electrical properties of the rock are linked to the hydrodynamic properties, primarily because both are affected by the fluid volume in the interstitial spaces of rock matrix. They inferred that the effective resistivity of the rock is the summation of individual resistivity response of components. In work by Givens (1986), Givens and Schmidt (1987) and Herrick (1989) for non-Archie rocks, the bulk resistivity

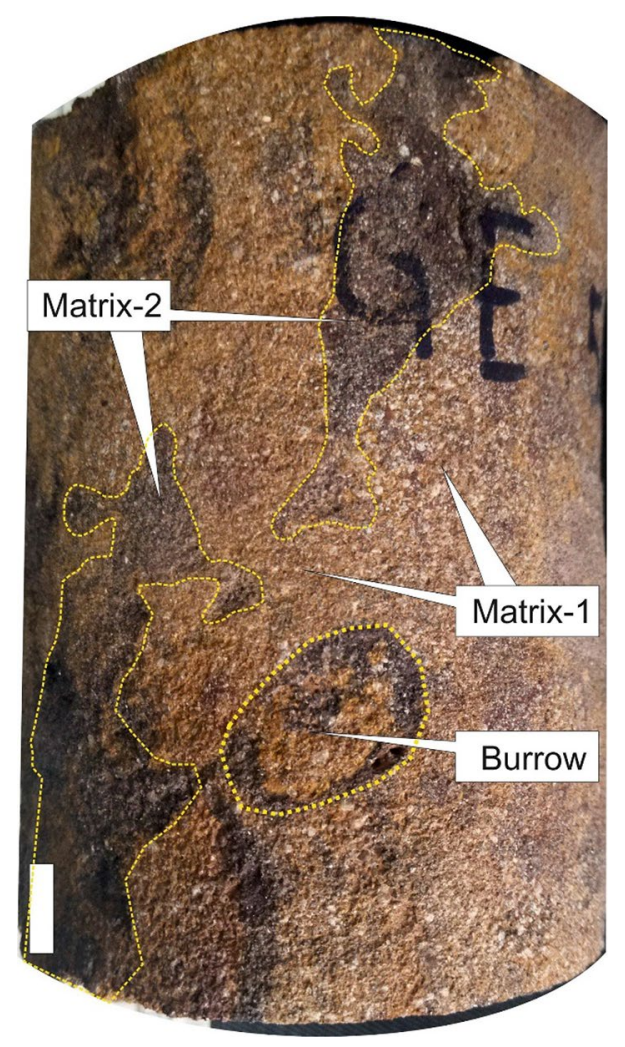

Fig. 4 Photograph of the heterogeneous bioturbated core plug depicting the: (i) bioturbated region, (ii) matrix 1 and (iii) matrix 2 in the specimen was considered to be an equivalent response of conducting pore network filled with fluid and rock fabric in a parallel arrangement.

The equivalent resistance network for triple-porosity model was assumed to have matrix and burrow in parallel arrangement, while the two matrixes to be in series connection with each other.

The previous reported work (Singh et al. 2018) had established that the burrow fill possesses a high permeability contrast to matrix in all samples of Ghuneri member. Also, the ichnofabric present in Ghuneri member has documented a similar trend in other hydrocarbon-producing formations (Gingras et al. 1999, 2007). Hence, the burrow region which has higher porosity and permeability will provide a less tortuous path for conduction of current and hence it is assumed to be in parallel connection with matrix. Also in the work by Saraf et al. (2019), the individual porosity of burrow and matrix was obtained through image processing of thin section images. The thin section images are not indicative of pore space connectivity but serve a quantitative estimate for pore volume. The result indicated a bimodal spread in porosity distribution for matrix region; hence, the two distinct class of porosity in matrix was thus classified as matrix 1 and matrix 2 . Being of very low porosity, these matrix classes will have a higher proportion of pore volume that will not assist in the flow of current. Therefore, similar to the model proposed in Aguilera and Aguilera (2004) where nonconnected vugs are taken in series, the matrix 1 and matrix 2 are assumed to be in series connection with each other.

\section{Cementation factor for burrow and matrix}

Archie (1942) observed the electrical properties of brinesaturated sandstone samples and formulated the relation between formation resistivity factor $(F)$ and porosity $(\phi)$

$F=\phi^{-m}$

where $m$ is the cementation factor obtained as the slope of the cross-plot between FRF and porosity on a log-log scale. In the modification by Winsauer et al. (1952), a term tortuosity factor " $a$ " was introduced in the Archie relation.

$F=a * \phi^{-m}$

The concept of tortuosity as introduced by Amyx et al. (1960) states that the ratio of actual passage length to the theoretical sample length is referred to as tortuosity factor " $a$ " and square of this ratio is called tortuosity " $\tau$ " (Fig. 5).

$\tau=\left(\frac{L_{a}}{L}\right)^{2}=(a)^{2}$ 


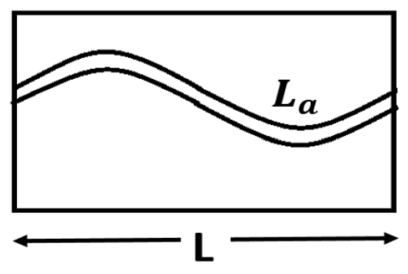

Fig. 5 A schematic layout for the concept of tortuosity (after Azar et al, 2008)

Theoretically, the minimum value of $\tau$ can be 1 , lower value than this is practically not possible. Perez-Rozalez and Luna (2004), (2005) suggested that not all the volume of porous space conducts electricity due to geometrical constraints; hence, the term flowing porosity was introduced by them. From this, it can be inferred that tortuosity obtained by the flow path of current is actually the apparent tortuosity $\left(\tau_{a}\right)$, not real tortuosity $(\tau)$.

For the triple-porosity model, due to the different grain size, sorting and texture of the burrow and the matrix, there will be a distinct geometry and degree of connectivity in pore volume. This would generate a large disparity in tortuosity and cementation factor values for each of them, though no published work has been reported for cementation factor of burrow, because of their complex and intricate nature. We propose that the approach to quantify cementation factor lies in the understanding of tortuosity present in them. The work by Wylie and Gregory (1952) obtained a minimum value of apparent porosity as 1.58 for packing of cube. Also, PerezRozalez and Luna (2004) have mentioned that the apparent tortuosity did not have a value higher than 4 for a vuggy fractured media. We anticipate that the apparent tortuosity for both burrow and matrix would fall under this window $1.5<\tau_{a}<4$ as both are limiting case, hence taking the value of $\tau_{a}$ as 1.5 for burrow and 4 for matrix and correspondingly the value of tortuosity factor as 1.22 and 2 , respectively, for burrow and matrix. The value of cementation factor obtained for burrow ranged from 1.54 to 2.04 with an average of 1.7, while that in matrix was from 2.84 to 3.39 with an average of 3.22. In development of triple-porosity model, we have assumed the same value of cementation factor for matrix 1 and matrix 2 .

\section{Model formulation}

This triple-porosity model proposed in the work provides a more comprehensive quantification of the cementation factor for bioturbated sandstone reservoir. The relation for evaluating cementation factor $\left(m_{t}\right)$ is given by Eq. 4 . The procedure for its derivation is discussed in Appendix A1. $m_{t}=\frac{-\log \left[\frac{\left[\left(\varnothing_{m 1}\right)^{-m+1}+\left(\varnothing_{m 2}\right)^{-m+1}\right\}}{\left[\left(\varnothing_{m 1}\right)^{(-m+1)}\left(\varnothing_{b}\right)^{\left(m_{b}+1\right)}+\left(\left(\varnothing_{m 2}\right)^{(-m+1)}\right)\left(\varnothing_{b}\right)^{(m b+1)}+\left(1-\varnothing_{B}\right)^{2}\right]}\right]}{\log \varnothing}$

where $m_{t}$ is the total cementation factor, $m$ is the cementation factor of matrix, $m_{b}$ is the cementation factor of burrow part, $\varnothing_{m 1}$ is the porosity of matrix $m_{1, \varnothing_{m 2}}$ is the porosity of matrix $m_{2}, \varnothing_{b}$ is the porosity of burrow part, and $\varnothing$ is the total porosity of the specimen.

The triple-porosity model given by Eq. 4 has functionality and can be applied to different degree of bioturbation intensity that may exist in the reservoir. For example, if the reservoir consists of no bioturbation, i.e., $\mathrm{BI}=0$, then the burrow porosity $\varnothing_{B}=0$, and Eq. 4 reduces to

$m_{t}=\frac{-\log \left[\left(\varnothing_{m 1}\right)^{-m+1}+\left(\varnothing_{m 2}\right)^{-m+1}\right]}{\log \varnothing}$

When the reservoir is completely bioturbated, i.e., $\mathrm{BI}=6$, the matrix porosities tend to be 0 ; therefore, Eq. 4 reduces to

$m_{t}=\frac{\log \left[\left(\varnothing_{b}\right)^{m_{b}+1}\right]}{\log \varnothing_{b}}$

Hence, the relation between cementation factor $m_{t}$ and burrow cementation factor $m_{b}$ comes to be

$m_{t}=m_{b}+1$

This relation states that the total cementation factor $m_{t}$ is always greater than the burrow cementation factor.

In certain conditions, when the reservoir may have same porosities for both the matrixes, i.e., $\varnothing_{m 1}=\varnothing_{m 2}$, Eq. 4 becomes

$m_{t}=\frac{-\log \left[\frac{\left(\varnothing_{m 1}\right)^{-m+1}}{\left[\left(\varnothing_{m 1}\right)^{(-m+1)}\left(\varnothing_{b}\right)^{(m b+1)}+{\frac{\left(1-\varnothing_{B}\right)^{2}}{2}}^{(-m}\right]}\right.}{\log \varnothing}$

\section{Results and discussion}

\section{Porosity variation}

The different bioturbated sandstones exhibited a wide variation in the porosities, both in the horizontal and in the vertical directions (Table 2); hence, further analysis will be discussed in the group of bioturbation index mentioned earlier. The porosity values for BI-2 samples ranged from 0.13 to 0.24 with an average of 0.17 and maximum distribution in range of vertical cores. For BI-4 samples, the porosity ranged from 0.15 to 0.25 . While samples of BI-5 
showed variation from 0.08 to 0.19 with an average of 0.14 , the larger distribution belonged to the vertical cores. The classification of porosity values in horizontal and vertical core was aimed to analyze bioturbation's effect due to selective orientation of burrows along the vertical axis which imparted disproportionate distribution of pore volume in the specimen. The horizontal direction variation is due to the presence of difference sediments between burrow and burrows wall material or some samples showing two types of a matrix with burrows (Fig. 4). The porosities obtained from image processing of the thin section image (Saraf et al. 2019) indicated bimodal distribution with a porosity of 0.04 to 0.05 and 0.11 to 0.12 class as the dominant value (Fig. 6a). This suggested a partitioning of matrix into two components matrix 1 and matrix 2 while generating triple porosity model. The porosity for burrow part was relatively larger at 0.2 to 0.22 as average pore size class (Fig. 6b). The higher porosity validates the previous understanding of enhanced porosity and permeability in contrast to matrix.
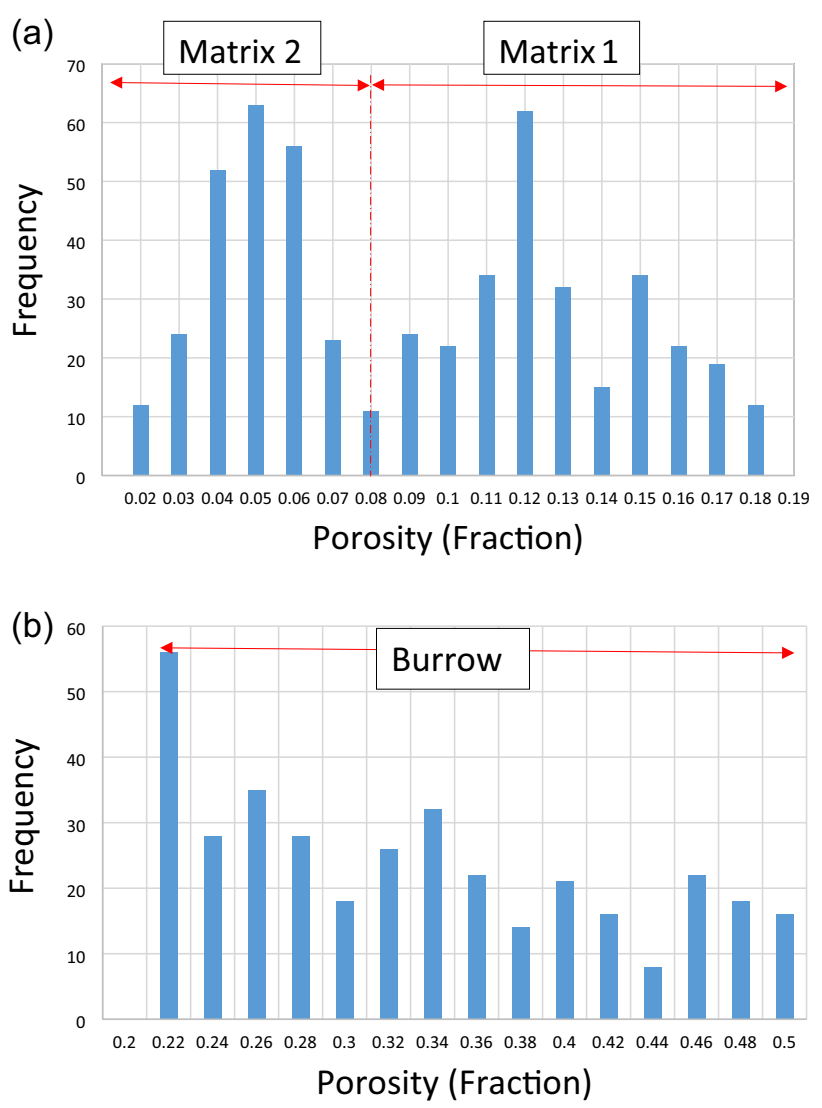

Fig. 6 a Frequency plot for porosity evaluated from thin section image of matrix part, $\mathbf{b}$ frequency plot for porosity evaluated from thin section image of burrow part

\section{FRF analysis}

As evident from Archie's equation (Eq. 1), the formation resistivity factor $(F)$ is inversely proportional to the porosity. Thus, lower-porosity samples will have a higher value of $F$ and vice versa.

Based on the limited availability of BI 4 samples, dataset for BI 2 and BI 5 specimens is selected for further analysis. In BI 2 specimens, the $F$ value ranged from 117 to 945 in horizontal core and in vertical core the $F$ value was between 61 and 658. The nature of distribution in $F$ value was analogous to porosity distribution in the same with larger scatter in vertical core, and the lowest value of $F$ was present in vertical core which was nearly half of that in horizontal cores. The reason that $F$ value bears more significant variation and lower $F$ value in vertical core than horizontal cores was due to the presence of vertically aligned burrows. The sampled vertical core had different proportions of these vertical burrows that assist in the decrease in electrical resistance of the void space as the coarser filled burrow has a reduced surface area-to-volume ratio (Atkins and Smith 1961; Pirson 1947), providing a less tortuous flow path along the longitudinal axis of the specimen.

On the other hand, in BI-5 specimen; for vertical core, the $F$ value ranged from 63 to 613 , and in horizontal core it varied from 155 to 352 . The range of $F$ for vertical core is similar but is substantially reduced for the horizontal core in comparison with BI-2 specimen. The BI-5 specimen has higher volume percentage (90\%) of burrow in the rock with increased density and overlapping (Taylor and Goldring $1993)$, so in conjunction with smaller sample size $(2.5 \mathrm{~cm})$, the horizontal core also has increased volume of the porous well-connected path of burrow, thereby reducing tortuosity. By comparing the FRF analysis of both BI-5 and BI-2 specimen, it can be inferred that the highest variation in tortuosity is obtained in vertical core in either specimen. The wellconnected least tortuous path in vertically aligned burrows is evident by the experimental FRF studies.

\section{Model validation}

In order to validate the cementation factor $m_{t}$ obtained from the triple-porosity model, a correlation between the corederived formation resistivity factor and formation resistivity factor obtained by cementation factor $m_{t}$ using the tripleporosity model was performed.

A cross-plot of formation resistivity factor vs porosity is plotted on the semilogarithmic scale for BI 5 specimen (Fig. 7). Based upon Eq. 4 for total cementation factor as per the triple-porosity model, a set of cementation factor values are generated following the assumption that the ratio of porosity of matrix 1 to matrix 2 is fixed; cementation factor for both the matrixes evaluated earlier was 3.22, while that 


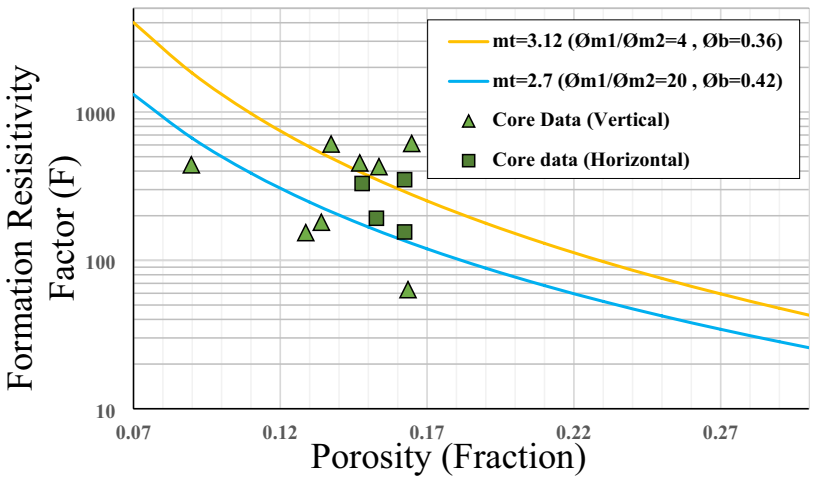

Fig. 7 Graph of F vs porosity for samples with bioturbation index 5 having matrix $m_{1}$ to matrix $m_{2}$ ratio of 4 and 20 respectively

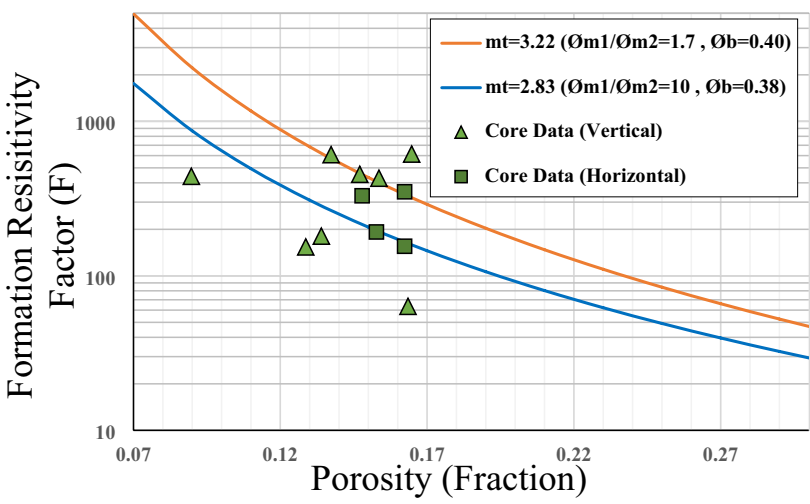

Fig. 8 Graph of $\mathrm{F}$ vs porosity for samples with bioturbation index 5 having matrix 1 to matrix 2 ratio of 1.7 and 10 respectively

for the burrow part was 1.7. A different value of burrow porosity is used with the necessary condition that burrow porosity is always higher than either of the matrix porosity fulfilled. The two solid lines represent the formation resistivity factor obtained for cementation factor $m_{t}$, as 3.12 and 2.7, respectively. The value of both the cementation factors is 3.12 and 2.7, the matrix porosity ratio is $\frac{\varnothing_{m 1}}{\varnothing_{m 2}}=4$ and 20 , while burrow porosity $\varnothing_{b}=0.36$ and $\varnothing_{b}=0.42$, respectively. Cross-plot of formation resistivity factor vs porosity crossplot for BI-5 represents the cementation factor with a value of 3.22 and 2.83 (Fig. 8). With the matrix porosity ratio being $\frac{\varnothing_{m 1}}{\varnothing_{m 2}}=1.7$ and 10 , burrow porosity $\varnothing_{b}=0.4$ and $\varnothing_{b}=0.38$, respectively.

A similar cross-plot of formation resistivity factor vs porosity for BI 2 specimen suggests that the cementation factor of 3 and 3.28 is obtained from the triple-porosity model for the matrix porosity ratio $\frac{\varnothing_{m 1}}{\varnothing_{m 2}}=32$ and 8 , while burrow porosity $\varnothing_{b}=0.42$ and $\varnothing_{b}=0.22$, respectively (Fig. 9). Similarly, the formation resistivity factor vs porosity crossplot (Fig. 10) shows that the cementation factors 3.18 and 3.67 were obtained for matrix porosity ratio being $\frac{\varnothing_{m 1}}{\varnothing_{m 2}}=16$

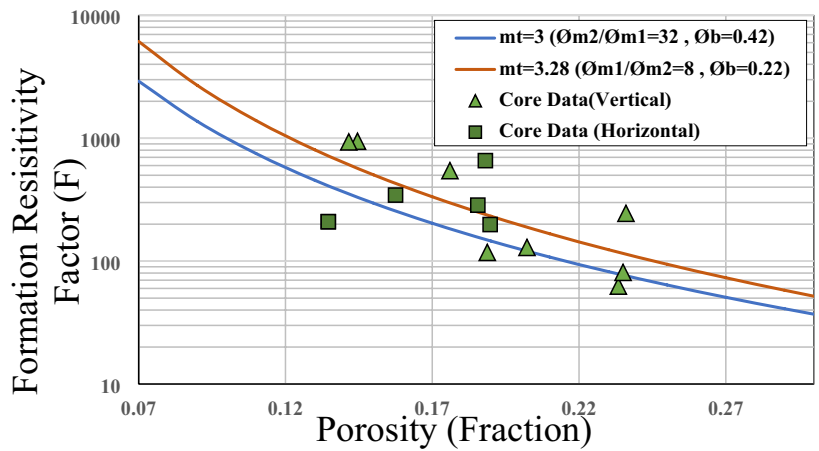

Fig. 9 Graph of $F$ vs porosity for samples with bioturbation index 2 having matrix 1 to matrix 2 ratio of 32 and 8 respectively

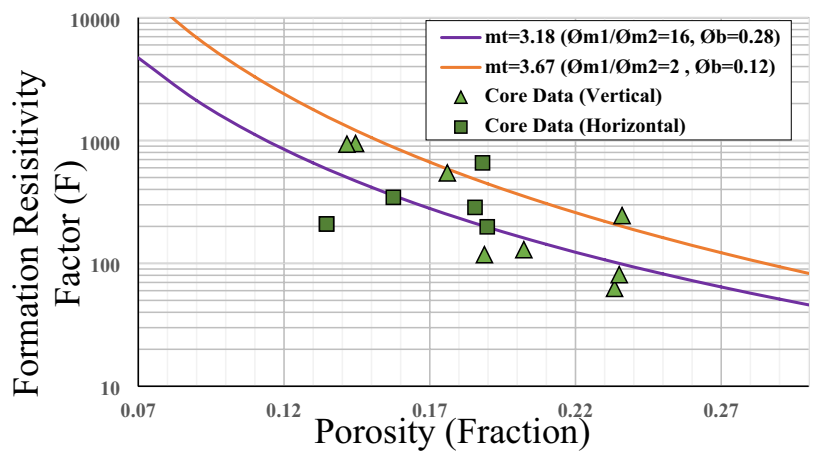

Fig. 10 Graph of $\mathrm{F}$ vs porosity for samples with bioturbation index 2 having matrix 1 to matrix 2 ratio of 16 and 2 respectively

and 2, while burrow porosity $\varnothing_{b}=0.28$ and $\varnothing_{b}=0.12$, respectively.

The study here analyzes the experimentally derived formation resistivity factor for bioturbated samples along with the cementation factor obtained using the triple-porosity model approach. Being a non-Archie rock, the bioturbated samples would not have a fixed set of cementation factor value, but different complex networks resulting from burrow and matrix arrangement will give rise to different cementation factor. These values are quantified based upon the triple porosity model. Although not all the point on the cross-plot could be utilized for validation, the lowest value of cementation factor in both samples was their limiting lower value. However, the solutions presented are not unique, a different set of matrix porosity ratio and burrow porosity can yield similar cementation factor value, but those values need to be practically consistent. The inherent assumption of burrow porosity being always more significant than either of matrix porosity needs to be satisfied; unrealistic values of matrix porosity though they give similar result have to be scrutinized while making any generalized comment. 


\section{Conclusion}

A comprehensive understanding of the bioturbation in porous media on electrical properties is discussed by developing a triple-porosity model to estimate total cementation factor. The clastic bioturbated rock is characterized into three components: matrix 1 , matrix 2 and bioturbated region. Based on the equivalent resistance model, an expression for evaluating total cementation factor in the form of matrix porosities and burrow porosity is developed. The model is beneficial in predicting the formation resistivity factor under a different set of bioturbation intensities by considering the individual porosities of the matrix and burrow. This helps in understanding the effect of bioturbation on the precise estimation of storage and flow properties. Inaccurate estimation of cementation factor can generate a significant error in the values of water saturation, thus underestimating or overestimating the hydrocarbon saturation, which is very important for economic evaluation.

\section{A1: Appendix}

Approach to improve triple porosity for heterogeneous bioturbated sandstone reservoir consisting of bioturbated region, matrix 1 and matrix 2 .

Considering the first series network for matrix $1\left(r_{m 1}\right)$ and matrix $2\left(r_{m 2}\right)$ as shown in Fig. 1

$r_{m}=r_{m 1}+r_{m 2}$

where

$r_{m}=R_{m} * L / A 1 ; r_{m 1}=R_{m 1} * L 1 / A 1 ; r_{m 2}=R_{m 2} * L 2 / A 2$

Inserting Eq. (2) into Eq. (1), we get

$R_{m} * \frac{L}{A 1}=R_{m 1} * \frac{L 1}{A 1}+R_{m 2} * \frac{L 2}{A 2}$

The volume of the system is defined as follows:

$V_{1}=A 1 L 1$

$V_{2}=A 2 L 2$

$V_{B}=\left(A-A_{1}\right) * L$

$V=V_{B}+V_{3}=A L$

$V_{3}=V_{m 1}+V_{m 2}=A 1 L=A 2 L$

$V_{3}=V_{m 1}+V_{m 2}=\varnothing_{m 1} V+\varnothing_{m 2} V=\left(\varnothing_{m 1}+\varnothing_{m 2}\right) V$ where $V_{1}=$ volume of matrix $1, V_{2}=$ volume of matrix 2 , $V_{B}=$ volume of bioturbated part, $V=$ total volume of the specimen, $V_{3}=$ cumulative volume of matrix 1 and matrix $2, \mathrm{~A}=$ cross-sectional area for both matrix system and bioturbated region, $A_{1}=$ cross-sectional area of matrix 1 , $A_{2}=$ cross-sectional area of matrix 2 .

For combined system of matrix 1 and matrix 2 in series,

$R_{m} * \frac{L}{A 1}=R_{m 1} * \frac{L 1}{A 1}+R_{m 2} * \frac{L 2}{A 2}$

$R_{m}=R_{m 1} *\left(\frac{A 1 L 1}{A 1 L}\right)+R_{m 2} *\left(\frac{A 1 L 2}{A 2 L}\right)$

Also,

$\left(A_{1}=A_{2}\right)$

$R_{m}=R_{m 1} *\left(\frac{A 1 L 1}{A 1 L}\right)+R_{m 2} *\left(\frac{A 1 L 2}{A 2 L}\right)$

$R_{m}=R_{m 1} *\left(\frac{V_{1}}{V_{3}}\right)+R_{m 2} *\left(\frac{V_{2}}{V_{3}}\right)$

The porosity of matrix 1, matrix 2 and bioturbated region is given by

$\varnothing_{m 1}=\frac{V_{m 1}}{V} ; \varnothing_{m 2}=\frac{V_{m 2}}{V} ; \varnothing_{B}=\frac{V_{B}}{V}$

From Fig. 11,

$V_{3}=V-V_{B}=V-\varnothing_{B} * V=V *\left(1-\varnothing_{B}\right)$

Equation 13 coefficient can be written as

$\frac{V_{1}}{V_{3}}=\frac{\varnothing_{m 1} * V}{\left(1-\varnothing_{B}\right) * V}=\frac{\varnothing_{m 1}}{1-\varnothing_{B}}$

$\frac{V_{2}}{V_{3}}=\frac{V_{3}-V_{1}}{V_{3}}=1-\frac{V_{1}}{V_{3}}=1-\frac{\varnothing_{m 1}}{1-\varnothing_{B}}=\frac{1-\varnothing_{B}-\varnothing_{m 1}}{1-\varnothing_{B}}=\frac{\varnothing_{m 2}}{1-\varnothing_{B}}$

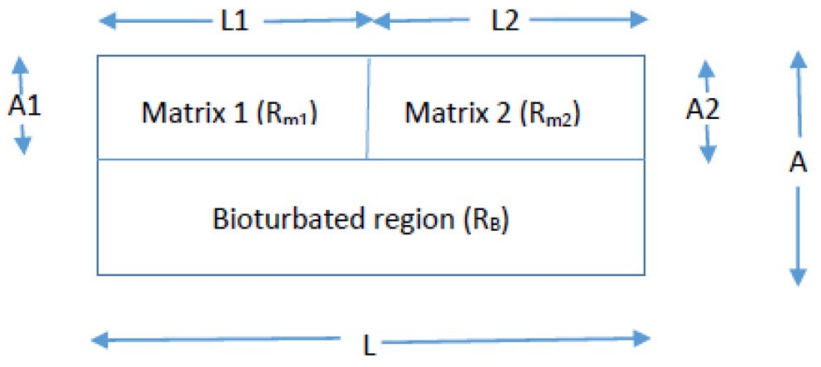

Fig. 11 Schematic of triple-porosity model (here, burrow is referred to bioturbated region) 
Inserting Eqs. (16) and (17) into Eq. (13), we get

$R_{m}=R_{m 1} *\left(\frac{\varnothing_{m 1}}{1-\varnothing_{B}}\right)+R_{m 2} *\left(\frac{\varnothing_{m 2}}{1-\varnothing_{B}}\right)$

The resistivity of the matrix and bioturbated region in the triple-porosity system is then

$R_{m}=\frac{R_{m 1} \varnothing_{m 1}+R_{m 2} \varnothing_{m 2}}{\left(1-\varnothing_{B}\right)}$

Consider the resistance network for matrix 1, matrix 2 and the bioturbated region combined system shown in Fig. 11:

$\frac{1}{r_{t}}=\frac{1}{r_{B}}+\frac{1}{r_{m}}$

where

$r_{m}=R_{m} * \frac{L}{A 1} ; r_{B}=R_{B} * \frac{L}{A-A 1} ; r_{t}=R_{t} * L / A$

Inserting Eq. (21) into Eq. (20), we get

$\frac{A}{R_{t} * L}=\frac{(A-A 1)}{R_{B} * L}+\frac{A 1}{R_{m} * L}$

$\frac{A L}{R_{t}}=\frac{(A-A 1) * L}{R_{B}}+\frac{A 1 L}{R_{m}}$

$\frac{1}{R_{t}}=\frac{\left(\frac{(A-A 1) L}{A L}\right)}{R_{B}}+\frac{\left(\frac{A 1 L}{A L}\right)}{R_{m}}$

$\frac{1}{R_{t}}=\frac{\frac{V_{B}}{V}}{R_{B}}+\frac{\frac{V_{3}}{V}}{R_{m}}$

$\frac{1}{R_{t}}=\frac{\varnothing_{B}}{R_{B}}+\frac{\varnothing_{m}}{R_{m}}$

$\frac{1}{R_{t}}=\frac{\varnothing_{B}}{R_{B}}+\frac{\left(1-\varnothing_{B}\right)}{R_{m}}$

$\frac{1}{R_{t}}=\frac{R_{m} \varnothing_{B}+R_{B\left(1-\varnothing_{B}\right)}}{R_{B} * R_{m}}$

$R_{t}=\frac{R_{B} R_{m}}{R_{m} \varnothing_{B}+R_{B}\left(1-\varnothing_{B}\right)}$

Inserting Eq. (19) into Eq. (23) yields
$R_{t}=\frac{R_{B}\left(\frac{R_{m 1} \varnothing_{m 1}+R_{m 2} \varnothing_{m 2}}{\left(1-\varnothing_{B}\right)}\right)}{\left(\frac{R_{m 1} \varnothing_{m 1}+R_{m 2} \varnothing_{m 2}}{\left(1-\varnothing_{B}\right)}\right) \varnothing_{B}+R_{B}\left(1-\varnothing_{B}\right)}$

$R_{t}=\frac{\frac{R_{B} R_{m 1} \varnothing_{m 1}+R_{B} R_{m 2} \varnothing_{m 2}}{\left(1-\varnothing_{B}\right)}}{\frac{R_{m 1} \varnothing_{m 1} \varnothing_{B}+R_{m 2} \varnothing_{m 2} \varnothing_{B}+R_{B}\left(1-\varnothing_{B}\right)^{2}}{\left(1-\varnothing_{B}\right)}}$

$R_{t}=\frac{R_{B} R_{m 1} \varnothing_{m 1}+R_{B} R_{m 2} \varnothing_{m 2}}{R_{m 1} \varnothing_{m 1} \varnothing_{B}+R_{m 2} \varnothing_{m 2} \varnothing_{B}+R_{B}\left(1-\varnothing_{B}\right)^{2}}$

The basic formation factor evaluation equation for only the matrix is

$R_{m 1}=F_{m 1} * R_{w}$

$R_{m 2}=F_{m 2} * R_{w}$

and

$F_{m 1}=\varnothing_{m 1}^{-m}$

$F_{m 2}=\varnothing_{m 2}^{-m}$

Here, we assume that $m_{1}=m_{2}=m$.

The extension of the basic formation factor evaluation equation for the triple-porosity reservoir is

$R_{t}=F_{t} * R_{w}$

$R_{B}=F_{B} * R_{w}$

and

$F_{t}=\varnothing^{-m t}$

$F_{B}=\varnothing^{-m B}$

Inserting Eq. (19) into Eq. (16), we get

$F_{t} R_{w}=\frac{R_{B} R_{m 1} \varnothing_{m 1}+R_{B} R_{m 2} \varnothing_{m 2}}{R_{m 1} \varnothing_{m 1} \varnothing_{B}+R_{m 2} \varnothing_{m 2} \varnothing_{B}+R_{B}\left(1-\varnothing_{B}\right)^{2}}$

$F_{t} R_{w}=\frac{R_{B}\left(R_{m 1} \varnothing_{m 1}+R_{m 2} \varnothing_{m 2}\right)}{R_{B}\left\{\frac{R_{m 1}}{R_{b}} \varnothing_{m 1} \varnothing_{B}+\frac{R_{m 2}}{R_{b}} \varnothing_{m 2} \varnothing_{B}+\left(1-\varnothing_{B}\right)^{2}\right\}}$

Canceling and rearranging the terms, we obtain the following equation:

$F_{t} R_{w}=\frac{\left(R_{m 1} \varnothing_{m 1}+R_{m 2} \varnothing_{m 2}\right)}{\left[\frac{R_{m 1}}{R_{b}} \varnothing_{m 1} \varnothing_{B}+\frac{R_{m 2}}{R_{b}} \varnothing_{m 2} \varnothing_{B}+\left(1-\varnothing_{B}\right)^{2}\right]}$ 
Also, expanding the resistivity in terms of formation factor and porosity using Eqs. (26) and (28):

$$
\begin{aligned}
& \varnothing^{-m t} \\
& {\left[\left(\varnothing_{m 1}\right)^{(-m+1)}\left(\varnothing_{b}\right)^{(m b+1)}+\left(\left(\varnothing_{m 2}\right)^{(-m+1)}\right)\left(\varnothing_{m b}\right)^{(m b+1)}+\left(1-\varnothing_{B}\right)^{2}\right]}
\end{aligned}
$$

When $m_{t}$ is isolated and Eq. (29) is rearranged, we obtain the following equation:

$m_{t}=\frac{-\log \left[\frac{\left[\left(\varnothing_{m 1}\right)^{-m+1}+\left(\varnothing_{m 2}\right)^{-m+1}\right\}}{\left[\left(\varnothing_{m 1}\right)^{(-m+1)}\left(\varnothing_{b}\right)^{(m b+1)}+\left(\left(\varnothing_{m 2}\right)^{(-m+1)}\right)\left(\varnothing_{m b}\right)^{(m b+1)}+\left(1-\varnothing_{B}\right)^{2}\right]}\right]}{\log \varnothing}$

This equation is used to calculate the cementation factor $\left(m_{t}\right)$ of the bioturbated triple-porosity system.

Acknowledgements The authors would like to acknowledge the research facilities provided at Petroleum Engineering Laboratory, School of Petroleum Technology, Pandit Deendayal Energy University.

Funding No funding.

\section{Declarations}

Conflict of interest On behalf of all the co-authors, the corresponding author states that there is no conflict of interest.

Open Access This article is licensed under a Creative Commons Attribution 4.0 International License, which permits use, sharing, adaptation, distribution and reproduction in any medium or format, as long as you give appropriate credit to the original author(s) and the source, provide a link to the Creative Commons licence, and indicate if changes were made. The images or other third party material in this article are included in the article's Creative Commons licence, unless indicated otherwise in a credit line to the material. If material is not included in the article's Creative Commons licence and your intended use is not permitted by statutory regulation or exceeds the permitted use, you will need to obtain permission directly from the copyright holder. To view a copy of this licence, visit http://creativecommons.org/licenses/by/4.0/.

\section{References}

Aguilera RF (1976) Analysis of natural fractured reservoirs from conventional well logs. J Petrol Technol 28(7):764-772. https://doi. org/10.2118/5342-PA

Aguilera RF (2010) Effect of fracture dip and fracture tortuosity on petrophysical evaluation of naturally fractured reservoir. J Can Pet Technol 49(9):69-76. https://doi.org/10.2118/139847-PA

Aguilera RF, Aguilera MS (2003) Improved model for petrophysical analysis of dual-porosity reservoir. Petrophysics 44(1):21-35

Aguilera RF, Aguilera R (2004) A triple porosity model for petrophysical analysis of naturally fractured reservoir. Petrophysics 45(2):157-166

Amyx JW, Bass DM, Whiting RL (1960) Petroleum reservoir engineering. McGraw-Hill Book Co., New York
Archie GE (1942) The electrical resistivity log as an aid in determining some reservoir characteristics. Trans AIME 146(1):54-62. https:// doi.org/10.2118/942054-G

Atkins ER, Smith GH (1961) The significance of particle shape in formation resistivity factor-porosity relationships. J Petrol Technol 13(3):285-291. https://doi.org/10.2118/1560-G-PA

Azar JH, Javaherian A, Pishvaie MR, Bidhendi MB (2008) An approach to defining tortuosity and cementation factor in carbonate reservoir rock. J Petrol Sci Eng 60:125-131. https://doi.org/ 10.1016/j.petrol.2007.05.010

Berg CR (2006) Dual-porosity equation from effective medium theory. In: SPE Annual Technical Conference and Exhibition, Society of Petroleum Engineer. doi:https://doi.org/10.2118/101698-MS.

Biswas SK (1977) Mesozoic rock-stratigraphy of Kutch. Quart J Geol Min Metall Soc India 49:1-52

Biswas SK, Deshpande SV (1970) Geological and tectonic map of Kutch (scale: 1inch=4 miles). ONGC Bull 7(2):115-123

Biswas SK (2016) Mesozoic and tertiary stratigraphy of Kutch (Kachchh): a review. In: Thakkar MG (ed) Recent studies on the geology of Kachchh. Special Publication of Geological Society of India vol 6, pp 1-24.

Bloss AR, Berosian AP (2015) Laboratory electrical resistivity analysis of geologic samples from fort Irwin, California. US Geol Surv Virg. doi:https://doi.org/10.3133/ofr20131024E

Desai BG, Chauhan S (2021) Taphonomic pathways for the formation of bioturbated cycles in the early cretaceous wave-dominated deltaic environment: Ghuneri Member, Kachchh Basin, India. In: Banerjee S, Sarkar S (eds) Mesozoic stratigraphy of India. Society of Earth Scientists Series. Springer, New York, pp 311-332. doi:https://doi.org/10.1007/978-3-030-71370-6_11

Desai BG, Saklani R (2012) Significance of the trace fossil Balanoglossites Mágdefrau, 1932 from the Lower Cretaceous Guneri member (Bhuj formation) of the Guneri dome, Kachchh, India. Swiss J Paleontol 131:255-263. https://doi.org/10.1007/ s13358-012-0045-8

Dorador J, Rodríguez-Tovar FJ, Miguez-Salas O (2021) The complex case of Macaronichnus trace fossil affecting rock porosity. Sci Rep 11:1-7. https://doi.org/10.1038/s41598-021-81687-6

Gingras MK, Pemberton SG (2014) Bioturbation: reworking sediments for better or worse. Oilfield Rev 26:46-58

Gingras MK, Pemberton SG, Mendoza C, Henk FH (1999) Modeling fluid flow in trace fossils; assessing the anisotropic permeability of Glossifungites surfaces. Petrol Geosci 5:349-357

Gingras MK, McMillan B, Balcom J, Saunders TD, Pemberton SG (2002) Using magnetic resonance imaging and petrographic techniques to understand the textural attributes and porosity distribution in Macaronichnus-burrowed sandstone. J Sediment Res 72(4):552-558

Gingras MK, Pemberton SG, Henk F, MacEachern JA, Mendoza C, Rostron B, O'Hare R, Spila M, Konhauser K (2007) Applications of ichnology to fluid and gas production in hydrocarbon reservoirs. Appl Ichnol Soc Econ Paleontol Mineral Short Course Notes 52:127-141

Gingras MK, Baniak G, Gordon J, Hovikoski J, Konhauser O, Croix A, Lemiski R, Mendoza C, Pemberton SG, Polo C, Zonneveld J (2012) Porosity and permeability in bioturbated sediments. Develop Sedimentol 64:835-868. https://doi.org/10.1016/B9780-444-53813-0.00027-7

Givens WW, Schmidt EJ (1987) A conductive rock matrix model (CRMM) for the analysis of low-contrast resistivity formation. Log Anal 28:138-151

Givens WW (1986) Formation factor, resistivity index, and related equations based upon a conductive rock matrix model (CRMM). Paper presented at the SPWLA 27th Annual Logging Symposium, Houston, Texas 
Herrick DC (1989) Conductivity model, Pore Geometry and Conduction Mechanism Paper presented at the SPWLA 29th Annual Logging Symposium, San Antonio, Texas

McPhee C, Reed J, Zubizretta I (2015) Best practice in coring and core analysis. Elsevier, Netherlands

Meadows PS, Tait J (1989) Modification of sediment permeability and shear strength by two burrowing invertebrates. Mar Biol 101:75-82

Pemberton SG, Gingras MK (2005) Classification and characterizations of biogenically enhanced permeability. AAPG Bull 89:1493-1517. https://doi.org/10.1306/07050504121

Perez-Rosales C, Luna E (2004) Characterization of a Vuggy Fractured Media: A Practical Approach. Paper presented at the SPE International Petroleum Conference in Mexico, Puebla Pue., Mexico, November 2004. doi:https://doi.org/10.2118/91863-MS

Perez-Rosales C, Luna E (2005) Naturally fractured reservoirs: how to estimate secondary porosity. Paper presented at the SPE Latin American and Caribbean Petroleum Engineering Conference, Rio de Janeiro, Brazil, June 2005. doi:https://doi.org/10.2118/ 94525-MS

Perret J, Prasher SO, Kantzas A, Langford C (1999) Three dimensional quantification of macropore networks in undisturbed soil cores. J Soil Sci Soc Am 63:1530-1543. https://doi.org/10.2136/sssaj 1999.6361530x

Pierret A, Capowiez Y, Belzunces L, Moran CJ (2002) 3D reconstruction and quantification of macropores using $\mathrm{X}$-ray computed tomography and image analysis. Geoderma 106:247-271

Pirson SJ (1958) Oil reservoir engineering. McGraw Hill Books Inc., New York

Pirson SJ (1947) Factors which affect true formation resistivity. Oil Gas J
Rasmus JC (1983) A variable cementation exponent $m$ for fractured carbonate. Log Anal 24:13-23

Saraf S, Singh A, Desai BG (2019) Application of microscopy image analysis for pore space and pore size distribution in bioturbated clastic rock. Int J Earth Sci Geol. https://doi.org/10.18689/26421569.a2.006

Singh A, Hazarika S, Dutta A, Madhavan N, Desai BG (2018) Enumerating the effect of bioturbation induced heterogeneity on petrophysical properties of clastic rocks using routine core analysis (RCA) and Special Core Analysis (SCAL) Second National Conference on Recent Studies on Geology of Kutch Basin

Taylor AM, Goldring R (1993) Description and analysis of bioturbation and ichnofabric. J Geol Soc 150:141-148

Winsauer WO, Shearin HM, Masson PH, Williams M (1952) Resistivity of brine-saturated sands in relation to pore geometry. AAPG Bull 36:253-277

Wylie MRJ, Gregory AR (1952) Formation factors of unconsolidated porous media: influence of particle shape and effect of cementation. Petrol Trans AIME 198:103-110

Xia L, Wenzhi Z, Cancan Z, Tongshan W, Chaoliu L (2012) Dual Porosity saturation model of low porosity and low permeability clastic reservoirs. Petrol Expl Develop 39(1):88-98. https://doi. org/10.1016/S1876-3804(12)60019-6

Publisher's Note Springer Nature remains neutral with regard to jurisdictional claims in published maps and institutional affiliations. 